\title{
Quantitative Characterization of Gold Nanoparticles by Field-Flow Fractionation Coupled Online with Light Scattering Detection and Inductively Coupled Plasma Mass Spectrometry
}

Schmidt, Bjørn; Löschner, Katrin; Hadrup, Niels; Mortensen, Alicja; Sloth, Jens Jørgen; Bender Koch, Christian; Larsen, Erik Huusfeldt

Published in:

Analytical Chemistry

Link to article, DOI:

10.1021/ac102545e

Publication date:

2011

Document Version

Publisher's PDF, also known as Version of record

Link back to DTU Orbit

Citation (APA):

Schmidt, B., Löschner, K., Hadrup, N., Mortensen, A., Sloth, J. J., Bender Koch, C., \& Larsen, E. H. (2011). Quantitative Characterization of Gold Nanoparticles by Field-Flow Fractionation Coupled Online with Light Scattering Detection and Inductively Coupled Plasma Mass Spectrometry. Analytical Chemistry, 83(7), 24612468. https://doi.org/10.1021/ac102545e

\section{General rights}

Copyright and moral rights for the publications made accessible in the public portal are retained by the authors and/or other copyright owners and it is a condition of accessing publications that users recognise and abide by the legal requirements associated with these rights.

- Users may download and print one copy of any publication from the public portal for the purpose of private study or research.

- You may not further distribute the material or use it for any profit-making activity or commercial gain

- You may freely distribute the URL identifying the publication in the public portal 


\title{
Quantitative Characterization of Gold Nanoparticles by Field-Flow Fractionation Coupled Online with Light Scattering Detection and Inductively Coupled Plasma Mass Spectrometry
}

\author{
Bjørn Schmidt, ${ }^{+,}$Katrin Loeschner, ${ }^{\ddagger}$ Niels Hadrup, ${ }^{\neq}$Alicja Mortensen, ${ }^{\ddagger}$ Jens J. Sloth, ${ }^{\neq}$ \\ Christian Bender Koch, ${ }^{\dagger}$ and Erik H. Larsen ${ }^{*, \neq}$ \\ ${ }^{\dagger}$ Department of Basic Sciences and Environment, University of Copenhagen, Thorvaldsensvej 40, DK-1871 Frederiksberg C, Denmark \\ ${ }^{\ddagger}$ National Food Institute, Technical University of Denmark, Mørkhøj Bygade 19, DK-2860 Søborg, Denmark \\ Supporting Information
}

\begin{abstract}
An analytical platform coupling asymmetric flow field-flow fractionation $\left(\mathrm{AF}^{4}\right)$ with multiangle light scattering (MALS), dynamic light scattering (DLS), and inductively coupled plasma mass spectrometry (ICPMS) was established and used for separation and quantitative determination of size and mass concentration of nanoparticles (NPs) in aqueous suspension. Mixtures of three polystyrene (PS) NPs between 20 and $100 \mathrm{~nm}$ in diameter and mixtures of three gold $(\mathrm{Au}) \mathrm{NPs}$ between 10 and $60 \mathrm{~nm}$ in diameter were separated by $\mathrm{AF}^{4}$. The

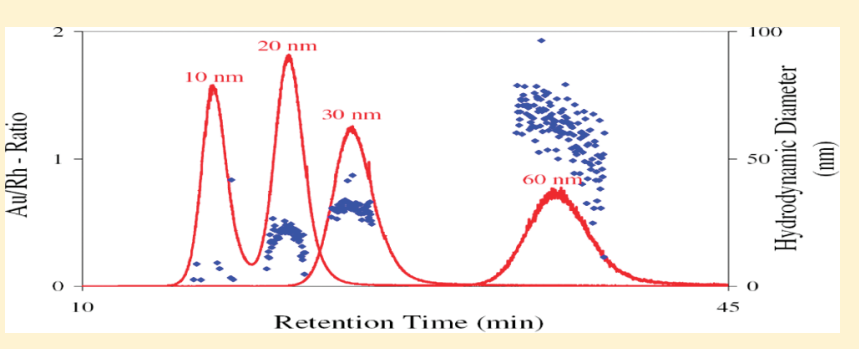
geometric diameters of the separated PS NPs and the hydrodynamic diameters of the Au and PS NPs were determined online by MALS and DLS, respectively. The three separated Au NPs were quantified by ICPMS and recovered at 50-95\% of the injected masses, which ranged between approximately 8-80 $\mathrm{ng}$ of each nanoparticle size. Au NPs adhering to the membrane in the separation channel was found to be a major cause for incomplete recoveries. The lower limit of detection (LOD) ranged between $0.02 \mathrm{ng} \mathrm{Au}$ and $0.4 \mathrm{ng} \mathrm{Au}$, with increasing LOD by increasing nanoparticle diameter. The analytical platform was applied to characterization of Au NPs in livers of rats, which were dosed with $10 \mathrm{~nm}, 60 \mathrm{~nm}$, or a mixture of 10 and $60 \mathrm{~nm}$ nanoparticles by intravenous injection. The homogenized livers were solubilized in tetramethylammonium hydroxide (TMAH), and the recovery of $\mathrm{Au}$ NPs from the livers amounted to $86-123 \%$ of their total Au content. In spite of successful stabilization with bovine serum albumin even in alkaline medium, separation of the Au NPs by $\mathrm{AF}^{4}$ was not possible due to association with undissolved remains of the alkali-treated liver tissues as demonstrated by electron microscopy images.
\end{abstract}

$\mathrm{T}$ he use of gold nanoparticles (Au NPs) can be dated back to the fifth century B.C. Throughout the 20th and at the beginning of the 21 st century, several methods on preparation of Au NP suspensions have been reported. ${ }^{1} \mathrm{Au}$ NPs were readily synthesized in the size range from 5 to $250 \mathrm{~nm}$ by reduction of chloroauric acid with sodium citrate. ${ }^{2,3}$ Since Au NPs can be successfully stabilized in suspension and have a reactive surface and unique optical properties, their applications within biology and medicine as carriers of bioactive molecules are of great interest. The surface of Au NPs can be conjugated with functional groups to serve a range of purposes. Most commonly, Au NPs were conjugated with citrate, transferrin, amino acids, oligonucleotides, peptides, antibodies, or lipids. ${ }^{4}$ These bioconjugates have primarily been used as labels for imaging techniques. In recent years, Au NP bioconjugates have received great interest as therapeutic agents where $\mathrm{Au}$ NPs function as vehicles for bioactive molecules. With respect to medical uses, a range of physicochemical properties may be of importance for assessment of possible toxicity of Au NPs and for assuring their safe use. In these contexts, properties of interest include mass concentration, size or size distribution, shape, state of agglomeration/ aggregation, and surface properties such as area, charge, reactivity, coating, and crystallite defects. ${ }^{5,6}$ However, most techniques used for detection of $\mathrm{Au}$ NPs in biological matrixes give qualitative information only.

In recent years, the use of inductively coupled plasma mass spectrometry (ICPMS) for quantitative analysis of Au NPs, either uncoated or bioconjugated, has gained interest. ${ }^{7-11}$ However, ICPMS cannot distinguish between particle sizes in a mixture of Au NPs, and the coupling to a separation technique prior to the ICPMS analysis is, therefore, required. The use of field-flow fractionation for separation of macromolecules such as proteins and polymers has been known since the late 1960s. ${ }^{12}$ It was not until 1999 that the first coupling between flow field-flow fractionation and ICPMS was reported and applied to environmental analysis. ${ }^{13}$ Since then, several research groups have applied this instrumental combination for fractionation and quantitative analysis of environmental NPs or macromolecules. ${ }^{14-23}$

Received: September 27, 2010

Accepted: February 4, 2011

Published: February 28, 2011 
Table 1. Instrumental Settings and $\mathrm{AF}^{4}$ Fractionation Program

\begin{tabular}{|c|c|}
\hline \multicolumn{2}{|c|}{ Mode $\mathrm{A}-\mathrm{AF}^{4}$ Separation Method for Au NPs and PS NPs } \\
\hline channel length & $154 \mathrm{~mm}$ \\
\hline spacer height & $350 \mu \mathrm{m}$ \\
\hline membrane type & polyethersulfone $10 \mathrm{kDa} \mathrm{MWCO}$ \\
\hline carrier liquid composition & $0.05 \% \mathrm{SDS}, 3 \% \mathrm{MeOH}$, and $20 \mu \mathrm{g} \mathrm{Rh} / \mathrm{L}$ in Milli-Q water \\
\hline elution flow & $0.5 \mathrm{~mL} / \mathrm{min}$ \\
\hline cross flow & $1 \mathrm{~mL} / \mathrm{min}$ \\
\hline focus flow & $2 \mathrm{~mL} / \mathrm{min}$ \\
\hline injection flow & $0.2 \mathrm{~mL} / \mathrm{min}$ \\
\hline makeup liquid composition & $3 \% \mathrm{MeOH}$ and $2 \% \mathrm{HNO}_{3}$ in Milli-Q water \\
\hline makeup liquid flow & $0.5 \mathrm{~mL} / \mathrm{min}$ \\
\hline step 1: elution with cross-flow & $0-1 \mathrm{~min}$ \\
\hline step 2: focus flow & $1-3 \mathrm{~min}$ \\
\hline step 3: injection with focus flow & $3-9 \min$ \\
\hline step 4: focus flow & $9-10 \mathrm{~min}$ \\
\hline step 5: elution with cross-flow & $10-60 \mathrm{~min}$ \\
\hline step 6: elution without cross-flow & $60-70 \mathrm{~min}$ \\
\hline
\end{tabular}

Mode B-Flow Injection of Au Calibration Standards

detector flow

carrier for calibration standards

makeup liquid composition

makeup liquid flow
$0.5 \mathrm{~mL} / \mathrm{min}$
$3 \% \mathrm{MeOH}, 2 \% \mathrm{HNO}_{3}$, and $20 \mu \mathrm{g} \mathrm{Rh} / \mathrm{L}$ in Milli-Q water
$3 \% \mathrm{MeOH}, 0.05 \% \mathrm{SDS}$ in Milli-Q water
$0.5 \mathrm{~mL} / \mathrm{min}$
In addition, size determinations can be obtained either with external size calibration by ultraviolet (UV) detection of polystyrene standards of known molecular weight or directly by multiangle light scattering (MALS) and/or dynamic light scattering (DLS).

The emerging use of Au NPs in biology and medicine, either as uncoated or bioconjugated NPs, calls for a versatile tool like asymmetric flow field-flow fractionation $\left(\mathrm{AF}^{4}\right)$-MALS/DLSICPMS for quantitative characterization of relevant metrics such as size and mass concentration. ${ }^{24}$ Online and direct determination of geometric diameters of nonabsorbing NPs in flow systems can be carried out by MALS, whereas DLS was used for determination of hydrodynamic diameters $\left(d_{h}\right)$ of NPs. Proper liberation of the NPs from biological samples into aqueous suspension prior to separation by $\mathrm{AF}^{4}$, however, remains an unsolved problem.

The objective of this work was to establish and characterize a hyphenated separation and detection platform for quantitative determination of size and mass concentration of Au NPs in suspension and to establish analytical validation parameters. To meet these objectives, $\mathrm{AF}^{4}$ was used for fractionation of NPs and was combined with MALS and DLS for obtaining size information and with ICPMS for mass concentration information of $\mathrm{Au}$ NPs. Finally, the feasibility of the platform for quantitative analysis of Au NPs contained in extracts of rat livers was tested.

\section{EXPERIMENTAL SECTION}

Chemicals and Nanoparticle Suspensions. Ultrapure Milli$Q$ water was obtained from a Millipore Element apparatus (Millipore, Milford, MA, USA) and used throughout the work. Nitric acid $(67-69 \%)$ and hydrochloric acid $(34-37 \%)$ of PlasmaPURE quality and single element PlasmaCAL standards of $\mathrm{Au}$ and $\mathrm{Rh}$ at $1000 \mu \mathrm{g} / \mathrm{mL}$ were obtained from SCP Science (Champlain, NY, USA). Sodium dodecyl sulfate (SDS, ReagentPlus $\geq 98.5 \%$ ) and bovine serum albumin (BSA) containing $\cong 98 \%$ protein monomer were obtained from Sigma-Aldrich (Milwaukee, WI, USA). Methanol (HPLC grade) was from Rathburn Chemicals Ltd. (Walkerburn, Scotland). A 25\% v/v aqueous solution of Electronic grade tetramethylammonium hydroxide (TMAH) was obtained from Alfa Aesar GmbH \& Co KG (Karlsruhe, Germany). Au NP aqueous stock suspensions at 10,20, and $60 \mathrm{~nm}$ in nominal diameters were obtained from British Biocell International (BBI, Cardiff, UK), but no information on concentration of $\mathrm{Au}$ was available. A certified reference $\mathrm{Au} \mathrm{NP}$ suspension at $30 \mathrm{~nm}$ in nominal diameter (RM8012) was obtained from the National Institute for Science and Technology, NIST (Gaithersburg, MD, USA). The mass fraction of the latter Au NP suspension was certified at $48.17 \pm$ $0.33 \mu \mathrm{g} / \mathrm{mL}$. Polystyrene (PS) NP Nanosphere stock suspensions at 20,60 , and $100 \mathrm{~nm}$ in diameter containing $1 \%$ solid were obtained from Thermo Fischer Scientific (Fremont, CA, USA) indicating a refractive index of 1.59 at $589 \mathrm{~nm}$.

Instrumentation. An Agilent 1200 series autosampler (G1329A) and a high performance liquid chromatography (HPLC) pump (G1311A; Agilent Technologies, Santa Clara, CA, USA) were used to inject NP working suspensions and to deliver the carrier flow, respectively. An $\mathrm{AF}^{4}$ Eclipse 3 instrument was used to regulate the cross-flow and detector flow of the carrier liquid delivered by the Agilent HPLC pump, in the $\mathrm{AF}^{4}$ separation channel. The optimized $\mathrm{AF}^{4}$ settings and flows used for separations of Au or PS NPs have been detailed in Table 1.

The $\mathrm{AF}^{4}$ channel was connected with a custom built DAWN HELEOS light scattering detector with a 17-channel MALS operated with a laser at $658 \mathrm{~nm}$ and equipped with a one-channel DLS option at the $99^{\circ}$ light scattering position (Wyatt Technology Europe $\mathrm{GmbH}$, Dernbach, Germany). Before starting the experiments, the sensitivities of 17 channels of the MALS detector were normalized relative to the $90^{\circ}$ detector by analysis of $20 \mathrm{~nm}$ PS NPs using the same fractionation program and carrier liquid as detailed in Table 1 . The MALS detector was set 
to a time sampling interval of $1 \mathrm{~s}$ per data point, and the DLS detector was set to a time sampling interval of $2 \mathrm{~s}$ per data point. Data from the light scattering detectors were processed using the ASTRA V software (version 5.3.2.15, Wyatt Technology Corporation, Santa Barbara, CA, USA). The 7500ce ICPMS instrument (Agilent Technologies, Santa Clara, CA, USA), which was equipped with a cooled Scott-type spray chamber and an Agilent Micro Flow nebulizer (model no. G3139A-100), was used for all ICPMS analyses. The instrument was run with an RF power of $1550 \mathrm{~W}$ and tuned for optimum sensitivity and low oxide ratio according to the manufacturer's instructions. The ICPMS was run in either spectrum-mode for quantitative analysis $(100 \mathrm{~ms}$ integration time per point with 5 repetitions) or in time-resolved acquisition mode (300 ms integration time per point with 1 repetition) using the Chemstation software (version B.03.05). A separate HPLC pump (Agilent 1100 series) delivered the relevant makeup solutions (Table 1 ) via a T-piece and through a mixing coil into the ICPMS (Figure S-1, Supporting Information). Two different modes, marked A and B, were used. Using mode A allowed fractionation and determination of NP size as well as post channel injections of Au NPs via a Rheodyne 7125 injector equipped with a $50 \mu \mathrm{L}$ sample loop (IDEX Health and Science LLC, Bristol, CT, USA). Mode B was used for flow injection (FI) of Au calibrant solutions. A switch valve directed either the NP analyte suspension or the calibrant solution to the ICPMS detector.

An Eppendorf (Hamburg, Germany) miniSpin centrifuge was operated at 13000 rounds per minute in conjunction with $12 \mathrm{kDa}$ molecular weight cutoff (MWCO) VectaSpin filters (Whatman, Kent, UK) to prepare ultrafiltrates of the Au NP stock suspensions. Microwave-assisted wet ashing was carried out using a Multiwave system equipped with high-pressure quartz vessels (Anton Paar, Graz, Austria). The microwave oven program for all analyses consisted of 3 steps: Step 1, a 5 min linear ramp from 200 to $1000 \mathrm{~W}$; step 2, holding the power at $1000 \mathrm{~W}$ for $20 \mathrm{~min}$; and step 3, cooling for $15 \mathrm{~min}$ at $0 \mathrm{~W}$. An ultrasonic bath operated at $185 \mathrm{~W}$ (Branson Ultrasonics Corporation, Danbury, CT, USA) was used to deagglomerate NP suspensions. An UltraTurrax homogenizer (IKA Werke GmbH \& Co. KG, Staufen, Germany) was used for preparation of slurries of biological tissues.

Quantitative Determination of Au in Au NP Stock Suspensions by ICPMS. Microwave-assisted digestions of $50 \mu \mathrm{L}$ of the $\mathrm{Au}$ NP stock suspensions or of $150 \mu \mathrm{L}$ of their ultrafiltrates were carried out using $2 \mathrm{~mL}$ of aqua regia $(1.5 \mathrm{~mL} \mathrm{HCl}$ and $0.5 \mathrm{~mL}$ $\mathrm{HNO}_{3}$ ) in triplicate. Furthermore, aqueous dilutions of the $\mathrm{Au}$ NP stock suspensions were subjected to analysis using direct nebulization into the ICPMS $\left({ }^{197} \mathrm{Au}\right)$ at "low", "medium", or "high" concentration (Table S-1, Supporting Information) and were quantified against external calibration curves using $\mathrm{Rh}$ $\left({ }^{103} \mathrm{Rh}\right)$ as internal standard.

Separation and Determination of Size and Mass of Au NP mixtures by $\mathrm{AF}^{4}-\mathrm{MALS} / \mathrm{DLS}-\mathrm{ICPMS}$. Mixtures of 10,20 , and $60 \mathrm{~nm} \mathrm{Au} \mathrm{NPs} \mathrm{or} \mathrm{a} \mathrm{suspension} \mathrm{of} 30 \mathrm{~nm} \mathrm{Au} \mathrm{NPs} \mathrm{at} \mathrm{"low",}$ "medium", or "high" concentrations (Table S-1, Supporting Information) were separated by $\mathrm{AF}^{4}$ using $50 \mu \mathrm{L}$ injections. Separate post channel injections of each Au NP size and concentration were used to calculate post channel recoveries. Following $\mathrm{Au} \mathrm{NP}$ separations and post channel injections, the platform was switched to mode $\mathrm{B}$ for introduction of Au calibrant solutions for construction of a calibration curve from 0 to $300 \mu \mathrm{g} \mathrm{Au} / \mathrm{L}$. The ICPMS signal intensity ratio ( $\mathrm{Au}$ divided by $\mathrm{Rh}$ ) for the fractogram or for the post channel peaks were converted to concentrations using the calibration curve, and by multiplication with the flow rate, an $\mathrm{Au}$ mass flow fractogram was obtained. Following peak integration, the absolute amounts of $\mathrm{Au}$ were calculated. Size calculations were performed at 50\% peak height to minimize the uncertainty of this determination. The Mie first order model of the ASTRA software was used for obtaining geometric diameters on the basis of the angular dependence of scattered light recorded by the MALS detector. The real part of the refractive index was set to 0.11 , and the imaginary part was set to 3.8. For hydrodynamic diameter calculations by DLS, the maximum fit delay time was set to $8.0 \times 10^{-4} \mathrm{~s}$.

Separation and Determination of Size of PS NP Mixtures by $\mathrm{AF}^{4}-\mathrm{MALS} / \mathrm{DLS}$. Mixtures of 20,60 , and $100 \mathrm{~nm}$ PS NPs at "low", "medium", or "high" concentrations (Table S-1, Supporting Information) were separated by $\mathrm{AF}^{4}$ using $50 \mu \mathrm{L}$ injections. Size calculations were performed for data recorded at $50 \%$ peak height using the same model as for Au NPs. However, only the real part of the refractive index (1.59) was applied for calculation of PS NP geometric diameters.

Characterization of Au NPs in Rat Livers by $\mathrm{AF}^{4}$-ICPMS. Sixteen female Wistar rats (4 weeks old with specific pathogenfree (SPF) health status from Taconic M\&B, Lille Skensved, Denmark) were administered Au NPs or a control medium by intravenous injection in a volume of $1 \mathrm{~mL}$ in the tail vein. The three dosage groups ( $N=4$ in each group) were administered 42.4, 41.3, and $41.7 \mu \mathrm{g}$ of $\mathrm{Au}$ as $10 \mathrm{~nm} \mathrm{NPs}, 60 \mathrm{~nm} \mathrm{NPs}$, or as an equal mixture (by mass) of 10 and $60 \mathrm{~nm}$ NPs, respectively, all suspended in an aqueous BSA solution at $1.3 \mathrm{mg} / \mathrm{mL}$. The animals of the control group $(N=4)$ were dosed $1 \mathrm{~mL}$ of the BSA solution. After $24 \mathrm{~h}$, the rats were euthanized (using anesthesia by $\mathrm{CO}_{2} / \mathrm{O}_{2}$ inhalation followed by decapitation) and livers were taken out, weighed, and subjected to further preparation and analysis. The animal study was performed under conditions approved by the Danish Agency for Protection of Experimental Animals and by the in-house Animal Welfare Committee.

The livers were homogenized in water $($ liver + water $=1+9$ $(\mathrm{w} / \mathrm{w}))$. The content of Au was determined following microwave-assisted wet ashing of $2 \mathrm{~mL}$ of tissue homogenate by aqua regia ( $3 \mathrm{~mL}$ of $\mathrm{HCl}$ and $1 \mathrm{~mL}$ of $\mathrm{HNO}_{3}$ ). The Au content was quantified by ICPMS against an external calibration curve using $\mathrm{Rh}$ as internal standard. The rat liver homogenate containing the highest $\mathrm{Au}$ concentration was selected from each dosage group for alkaline extraction and nanoparticle analysis. BSA was added to $2 \mathrm{~mL}$ of liver homogenate at approximately 10-fold excess by mass relative to the gold content. TMAH was then added to a final concentration of $5 \%(\mathrm{v} / \mathrm{v})$. The samples were ultrasonicated for $1 \mathrm{~h}$ and rotated mechanically at room temperature overnight. The alkaline extracts were analyzed on the $\mathrm{AF}^{4}$-MALS/ DLS-ICPMS platform by the same method as used for the $\mathrm{Au} \mathrm{NP}$ characterizations, except increasing the injected volume to $500 \mu \mathrm{L}$.

Electron Microscopy. In order to evaluate membrane adhesion phenomena of Au NPs, a fresh polyethersulfone (PES) membrane was mounted in the $\mathrm{AF}^{4}$ separation channel and 6 consecutive injections of the "high" concentration Au NP mixture were run. The PES membrane was then removed and left to dry for $2 \mathrm{~h}$ in a fume hood. Pieces of approximately 5 $\mathrm{mm}$ by $5 \mathrm{~mm}$ of the membrane were mounted on stubs using conductive carbon adhesive tabs and sputter coated with chromium. The samples were analyzed by a Philips XL 30 FEG scanning electron microscope (SEM) operated in the 


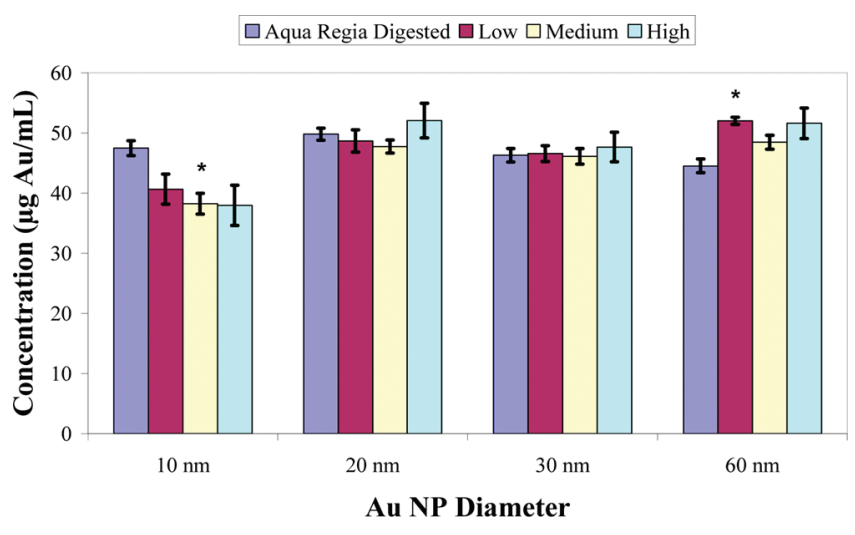

Figure 1. Quantitative determination of Au in stock suspensions of four sizes of Au NPs using direct nebulization of working suspensions at "low", "medium", or "high" Au concentration into the ICPMS (see Table S-1, Supporting Information). The Au concentration of aqua regia digested $\mathrm{Au}$ NPs were used as reference. The columns and error bars indicate mean values \pm one standard deviation $(N=3)$. Significant differences in concentration $(p<0.05)$ between directly nebulized Au NPs and aqua regia digested Au NPs are indicated by asterisk.

backscattered-electron mode at an accelerating voltage of $20 \mathrm{kV}$ (FEI, Eindhoven, Netherlands).

Nanoparticles in suspension were imaged using a Philips CM100 transmission electron microscope (TEM) at $100 \mathrm{kV}$ accelerating voltage (FEI, Eindhoven, Netherlands). A drop of each of the "high" concentration working suspension, the "residual" fraction following $\mathrm{AF}^{4}$ separation, and the alkali treated liver tissue of one rat (diluted approximately 10 times with deionized water) were applied to a 200 mesh copper grid coated with lacey carbon film and left to dry prior to TEM imaging. Generally, 10 random positions on each electron microscopy grid were investigated to ensure that representative images were obtained.

Data Handling and Analysis. Further data processing of light scattering or ICPMS data and one-way ANOVA or linear regression analysis was carried out using a spread sheet (Microsoft Office Excel 2003, Microsoft Corporation, Redmond, WA, USA). Peak integrations were carried out using OriginPro 8.1 (OriginLab Corporation, Northampton, MA, USA).

\section{RESULTS AND DISCUSSION}

Quantitative Analysis. ICPMS analysis of ultrafiltrates of the $\mathrm{Au}$ NP stock suspensions showed that the Au concentration in the filtrates was below the limit of detection and confirmed that all $\mathrm{Au}$ in the Au NP stock suspensions was present as nanoparticles. In order to carry out quantitative analyses and recovery experiments of $\mathrm{Au}$ NPs by $\mathrm{AF}^{4}$-ICPMS, it was necessary to accurately determine the concentration of $\mathrm{Au}$ in the 10,20, and $60 \mathrm{~nm} \mathrm{Au} \mathrm{NP} \mathrm{stock} \mathrm{suspensions.} \mathrm{The} \mathrm{results} \mathrm{(Figure} \mathrm{1)} \mathrm{demon-}$ strated that the determined $\mathrm{Au}$ content in the acid digested $30 \mathrm{~nm}$ NIST reference Au NP stock suspension was in accordance with the certified value of $48.17 \pm 0.33 \mu \mathrm{g} \mathrm{Au} / \mathrm{mL}$. Furthermore, quantitative results for Au following direct nebulization of the 20 and $30 \mathrm{~nm}$ Au NP working suspensions into the ICPMS did not deviate from their acid digested counterparts. This finding illustrated that the ionization of Au NPs in the ICP was complete for the tested Au NP sizes and concentration range.

In contrast, similar results for the 10 and $60 \mathrm{~nm} \mathrm{Au} \mathrm{NPs}$ showed slight but significant differences for the "medium" concentration of $10 \mathrm{~nm}$ Au NP and the "low" concentration of the $60 \mathrm{~nm} \mathrm{Au} \mathrm{NPs} \mathrm{working} \mathrm{suspensions} \mathrm{when} \mathrm{compared} \mathrm{with}$ their acid digested counterparts. These differences may be explained by losses due to adhesion to instrument surfaces particularly of the $10 \mathrm{~nm} \mathrm{Au} \mathrm{NPs} \mathrm{or} \mathrm{by} \mathrm{random} \mathrm{release} \mathrm{of}$ deposited large $(60 \mathrm{~nm})$ particles from previous experiments. The random noise of the time-resolved ICPMS signals (Figure S-2, Supporting Information) increased with increasing diameter of the directly nebulized Au NPs. Assuming a nebulization efficiency of $1 \%^{25}$ and using an uptake rate of $0.33 \mathrm{~mL} / \mathrm{min}$ of the nanoparticle suspensions, the calculated mean number of particles reaching the ICP during each 300 ms ICPMS integration time ranged from 8800 for the $10 \mathrm{~nm} \mathrm{Au} \mathrm{NPs} \mathrm{to} 33$ for the $60 \mathrm{~nm}$ Au NPs. The observed increasing noise with increasing Au NP sizes may be due to short-term fluctuations in number density of the larger Au NPs reaching the ICP or may be caused by adhesion-release phenomena of the NPs. Thus, when introducing suspensions of the Au NPs directly into the ICPMS, the observed noise characteristics of the time-resolved signal was of diagnostic importance.

Instrumental Platform. The combined instruments (Figure S-1, Supporting Information) were used to separate mixtures of $\mathrm{Au}$ NPs or of PS NPs and to provide information on retention time, NP size, and mass concentration of $\mathrm{Au}$ in Au NP suspensions. The composition of carrier liquid, however, was of importance for assuring NP stability during separation. SDS, which has been commonly used as a surfactant in aqueous carrier liquids for $\mathrm{AF}^{4}$, proved to be superior to pure water for both types of NPs. Tests of the influence of bottom membrane material of the $\mathrm{AF}^{4}$ cell showed that PES with a $10 \mathrm{kDa} \mathrm{MWCO}$ was superior to regenerated cellulose and led to larger peak areas and closer approximation to Gaussian shape of the fractogram peaks.

In contrast to a previously reported instrumental setup for quantitative NP analysis, ${ }^{13}$ attempts to quantify Au NPs by flow injection of calibrant solutions through the $\mathrm{AF}^{4}$ cell (using zero cross-flow) and using SDS as carrier caused loss of calibrant due to precipitation. Therefore, in the present work, flow injection (mode B; Figure S-1, Supporting Information) was used for introduction of the calibrant solutions but required additional introduction of a makeup liquid (Table 1). Being a surfactant, SDS in the carrier liquid affected the nebulization efficiency while the optimum $3 \%$ methanol was added to enhance and stabilize the ionization efficiency of Au. ${ }^{26}$ The purpose of the makeup liquid was, therefore, to ensure the flow rate and composition of the combined solvents reaching the ICPMS were constant for modes A and B at any time of analysis.

NP separation and flow injection of calibration standards into the $\mathrm{AF}^{4}$ system coupled with ICPMS were successfully used for analysis of uranium associated with dissolved organic matter without the need for separate flow streams and makeup liquids and was applied. ${ }^{14}$ However, in the present work, the mentioned risk of losses of Au calibrants by precipitation required a more elaborate but also more universal instrumental setup for metallic nanoparticles.

Separation and Quantitative Analysis of Au NPs in Aqueous Suspension. The $\mathrm{AF}^{4}$ method was optimized for separation of mixtures of 10, 20, and $60 \mathrm{~nm}$ Au NPs and for mixtures of 20, 60, and $100 \mathrm{~nm}$ PS NPs, respectively. In comparison with $\mathrm{AF}^{4}$, separation of Au NPs by hydrodynamic chromatography or by size exclusion chromatography ${ }^{7,8}$ has produced results that are equal to or poorer than the separation efficiency achieved in the present work. The fractograms corresponding to a mixture of $\mathrm{Au}$ 


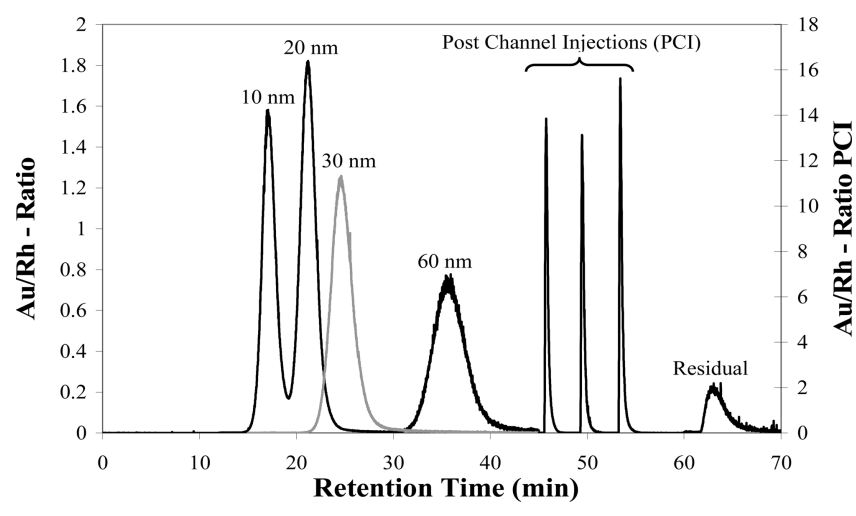

Figure 2. $\mathrm{AF}^{4}-\mathrm{ICPMS}$ fractogram of a mixture of 10,20 , and $60 \mathrm{~nm} \mathrm{Au}$ NPs (black line) superimposed on a fractogram corresponding to $30 \mathrm{~nm}$ NIST Au NPs (light gray line) all at "high" concentrations (see Table S-1, Supporting Information). The signal intensities of post channel injections of 10, 20, and $60 \mathrm{~nm}$ Au NPs have been indicated on the secondary $y$-axis. For explanation of "residual" Au NPs, see text. Injected volumes, $50 \mu \mathrm{L}$.

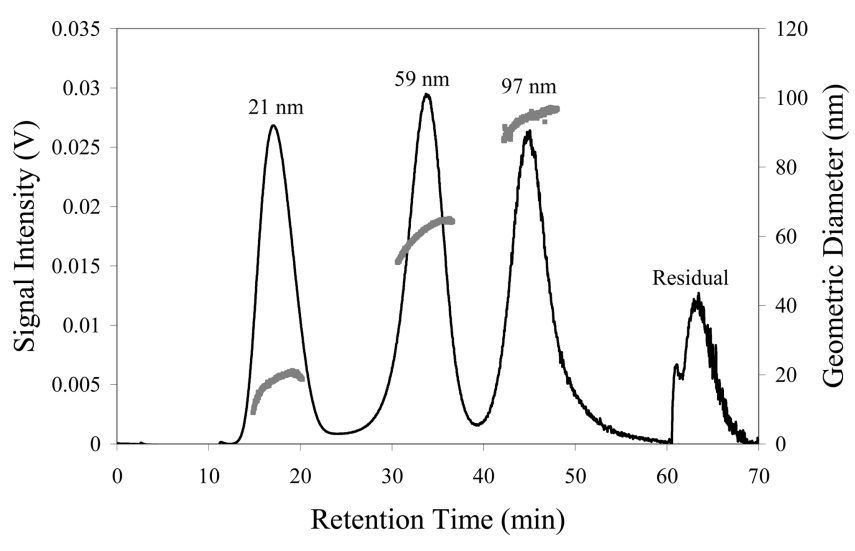

Figure 3. $\mathrm{AF}^{4}$-MALS fractogram of a mixture of 21,59 , and $97 \mathrm{~nm}$ PS NPs at "high" concentration (see Table S-1, Supporting Information) showing the response for the $90^{\circ}$ detector indicated on the primary $y$-axis. Geometric diameters are shown in gray color across each peak indicated on the secondary $y$-axis.

NPs (Figure 2) and to a mixture of PS NPs (Figure 3) showed that separation into their components was successfully achieved. For both mixtures of NPs, however, a peak from "residual" NPs occurred when the cross-flow of the $\mathrm{AF}^{4}$ program, in its final stage, was set to zero. A TEM image of the collected "residual" peak following $\mathrm{Au}$ NPs separation revealed the presence of distinct $\mathrm{Au}$ NPs of the same size as those detected in the mixture of stock suspensions of 10, 20, and $60 \mathrm{~nm} \mathrm{Au} \mathrm{NPs} \mathrm{(Figure} \mathrm{4B,D).} \mathrm{This}$ observation supported that the "residual" $\mathrm{AF}^{4}$ peak corresponded to released Au NPs that were adhered to the membrane or were associated with nonspecific particulate matter, which originated from the carrier liquid or bled from the membrane.

Before quantitative Au NP analyses were carried out, a newly mounted bottom membrane of the $\mathrm{AF}^{4}$ cell was conditioned and showed a gradually increasing recovery throughout the six repeated injections of Au NPs. Following this conditioning, the results from the quantitative Au NP determinations were recorded and the results (Table 2) have been presented as retention time, recovery, repeatability, and limit of detection for four sizes and three levels of injected masses of Au NPs. A one-way ANOVA showed no difference $(p<0.05)$ in mean recovery of the 10,20, and $60 \mathrm{~nm} \mathrm{Au} \mathrm{NPs} \mathrm{for} \mathrm{each} \mathrm{of} \mathrm{the} \mathrm{three}$ injected $\mathrm{Au}$ masses. For the $30 \mathrm{~nm} \mathrm{Au} \mathrm{NP}$, however, a small difference between the recoveries of the three injected masses was tested statistically significant $(p<0.05)$ due to the low standard deviation of the repeated determinations. The mean recoveries, which were corrected for post channel recovery, ranged between 50 and $95 \%$ of the injected masses of Au NPs. The mass of $\mathrm{Au}$ recovered in the residual peaks amounted to approximately $2 \%$ of the total mass of injected Au. The incomplete recovery rates were, in spite of the conditioning, likely to be caused by losses due to adhesion of Au NPs to instrument surfaces, including the $\mathrm{AF}^{4}$ bottom membrane. Scanning electron microscopy (SEM; Figure 4A) revealed that particles indeed were adsorbed to the membrane, thereby explaining part of the reason for the incomplete recoveries. Losses occurring after the $\mathrm{AF}^{4}$ separation channel, which included visible buildup of $\mathrm{Au}$ on the tip of the nebulizer and ICPMS injector tube, were, however, corrected by the recovery of gold in the postchannel injections. The sum of Au masses corresponding to each peak of the fractogram, including the residual peak, amounted between 96 and $99 \%$ of the total separated $\mathrm{Au}$ mass estimated from the area of the entire fractogram. This demonstrated that virtually all Au was accounted for when integrating each fractogram peak separately.

The retention times $\left(T_{\mathrm{r}}\right)$ recorded for each of four sizes of $\mathrm{Au}$ NPs (Table 2) did not differ between injected masses $(p<0.05)$, which indicated that particle - particle or particle - membrane interactions were insignificant given the experimental conditions used. ${ }^{27}$ A linear relation $\left(r^{2}=0.9998\right)$ between $T_{\mathrm{r}}$ and the measured $d_{\mathrm{h}}$ was observed for the separated mixture of 10,20 , and $60 \mathrm{~nm}$ Au NPs (Figure S-3, Supporting Information). Similar

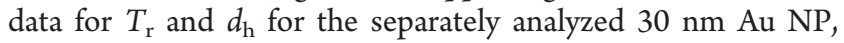
which were in accordance with the certified hydrodynamic diameter, served the purpose of validating the established linear relation. Therefore, the linear relation can be used for estimation of $d_{\mathrm{h}}$ for unknown Au NP samples at low concentrations from their $T_{\mathrm{r}}$ in the ICPMS fractogram. However, this conclusion relied on equal retention behavior of the analyte and calibrant Au NPs.

Direct Size Determination of PS and Au NPs by Light Scattering. Generally, information on sizes of nanoparticles is an important metric for understanding their distribution or effects in biological systems. The results from the online determination of the diameter of PS NPs (Table 3) by MALS demonstrated that the values were in agreement with the stated certified values at the "medium" and "high" concentrations. At the "low" concentration of NP working suspension, however, the intensity of the scattered light was too low to detect any angular dependency; thus, accurate size information could not be obtained. In contrast, MALS could not be applied for sizing of the Au NPs because the angular dependency of light scattered by Au NPs in this size range was too weak when the $658 \mathrm{~nm}$ laser wavelength was used. An approach to sizing of Au NPs by MALS would be the use of a laser light source with a shorter wavelength, e.g., to $405 \mathrm{~nm}$, which would lead to a stronger angular dependence of light scattered and thereby allow determination of their size down to $20 \mathrm{~nm}$ (Daniel Some; Wyatt Technology Corporation; personal communication). Nevertheless, determination of $d_{\mathrm{h}}$ by online DLS was possible but was accurate only for Au and PS working suspensions at "high" concentration (Tables 2 and 3, respectively) because of inferior sensitivity of this LS technique. No reliable information on sizes of Au NP and PS NP sizes could 

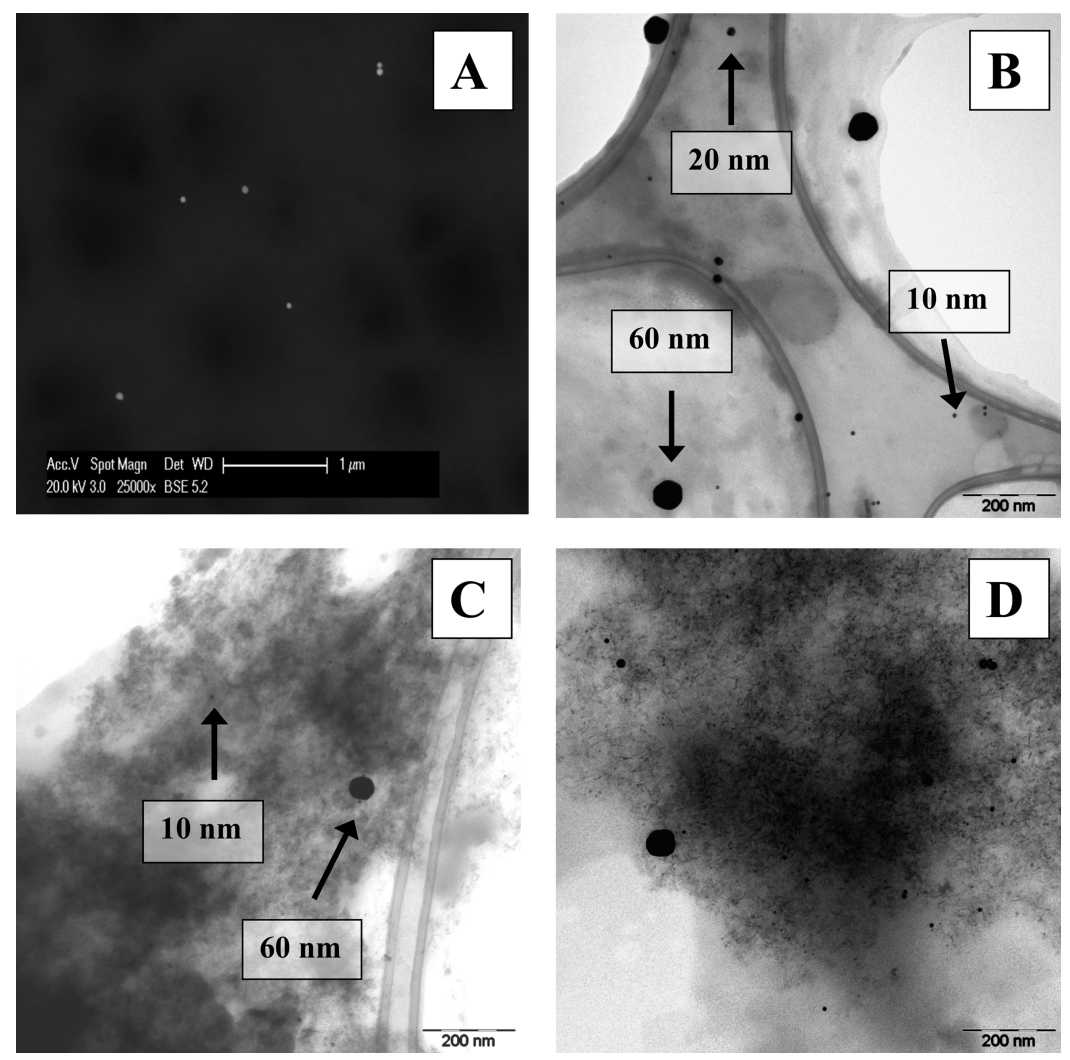

Figure 4. SEM and TEM pictures of Au NPs. (A) Backscattered-electron mode SEM image of Au NPs adhered to the $\mathrm{AF}^{4}$ separation channel membrane, (B) TEM image of an undiluted mixture of 10, 20, and $60 \mathrm{~nm}$ Au NPs on a lacey carbon film, (C) TEM image of a TMAH liver extract on a lacey carbon film, and (D) TEM image of the "residual" $\mathrm{AF}^{4}$ peak for "high" concentration Au NPs.

Table 2. Results from $\mathrm{AF}^{4}$-DLS-ICPMS Analyses of Au NPs

\begin{tabular}{|c|c|c|c|c|c|c|}
\hline $\begin{array}{l}\text { NP diameter } \\
\quad(\mathrm{nm})^{a}\end{array}$ & $\begin{array}{l}\text { injected } \\
\text { mass (ng) }\end{array}$ & $\begin{array}{c}\text { retention } \\
\text { time }(\text { minutes })^{b}\end{array}$ & $\begin{array}{l}\text { recovery } \\
(\%)^{b, c}\end{array}$ & $\begin{array}{l}\text { overall recovery } \\
(\%)^{c, d}\end{array}$ & $\begin{array}{c}\text { hydrodynamic } \\
\text { diameter }(\mathrm{nm})^{b, e}\end{array}$ & $\begin{array}{l}\text { ICPMS limit of } \\
\text { detection }(\mathrm{ng})^{f}\end{array}$ \\
\hline \multirow{3}{*}{9.8} & 7.9 & $7.6 \pm 0.2$ & $50 \pm 20$ & & ND & \\
\hline & 19.8 & $7.5 \pm 0.4$ & $53 \pm 19$ & $50 \pm 15$ & ND & 0.02 \\
\hline & 79.1 & $7.0 \pm 0.1$ & $46 \pm 11$ & & $10 \pm 4.4$ & \\
\hline \multirow{3}{*}{20.4} & 8.3 & $11.4 \pm 0.2$ & $98 \pm 21$ & & ND & \\
\hline & 20.7 & $11.5 \pm 0.2$ & $88 \pm 8.3$ & $95 \pm 15$ & ND & 0.2 \\
\hline & 83.0 & $11.3 \pm 0.1$ & $99 \pm 17$ & & $21 \pm 1.3$ & \\
\hline \multirow{3}{*}{28.6} & 7.7 & $14.2 \pm 0.1$ & $84 \pm 3.2$ & & ND & \\
\hline & 19.3 & $14.4 \pm 0.3$ & $75 \pm 2.1$ & & ND & 0.3 \\
\hline & 77.1 & $14.4 \pm 0.2$ & $75 \pm 3.8$ & & $31 \pm 0.3$ & \\
\hline \multirow{3}{*}{58.7} & 7.4 & $25.4 \pm 0.3$ & $70 \pm 17$ & & ND & \\
\hline & 18.6 & $25.8 \pm 0.3$ & $73 \pm 3.9$ & $67 \pm 11$ & ND & 0.4 \\
\hline & 74.2 & $25.6 \pm 0.2$ & $57 \pm 2.8$ & & $62 \pm 0.6$ & \\
\hline
\end{tabular}

${ }^{a}$ Nominal geometric diameters for 9.8, 20.4, and $58.7 \mathrm{~nm}$ NPs and nominal hydrodynamic diameter for the $28.6 \mathrm{~nm}$ NPs as given by manufacturers.

${ }^{b}$ Mean values \pm one standard deviation $(N=3) .{ }^{c}$ In relation to injected mass and corrected for recovery of post channel injections. ${ }^{d}$ Mean values \pm one standard deviation $(N=9) .{ }^{e} \mathrm{ND}$ denotes not determined. ${ }^{f}$ Corrected for recovery.

be obtained for lower concentrations indicating that the intensity of the scattered light was too low. Even though the number density of the $10 \mathrm{~nm} \mathrm{Au} \mathrm{NPs} \mathrm{was} \mathrm{approximately} \mathrm{8-times} \mathrm{larger}$ than that of the $20 \mathrm{~nm}$ Au NPs at the "high" concentration, the proportionality between the intensity of the scattered light and the sixth power of particles' diameter led to weak DLS signals for the smaller particle, and consequently, the determined size of the $10 \mathrm{~nm} \mathrm{Au} \mathrm{NP}$ particle was associated with large standard deviation.

Determination of Au NPs in Rat Tissues by $\mathrm{AF}^{4}$-ICPMS. In order to liberate the Au NPs from the livers, the homogenized tissues (Table 4) were subjected to alkaline dissolution by 
Table 3. Results from $\mathrm{AF}^{4}$-DLS/MALS Analyses of PS NPs

\begin{tabular}{lccc} 
& & \multicolumn{2}{c}{ diameter $(\mathrm{nm})^{b}$} \\
\cline { 3 - 4 } NP diameter $(\mathrm{nm})^{a}$ & injected mass $(\mathrm{ng})$ & hydrodynamic & geometric \\
& & & \\
$21 \pm 1.5$ & 500 & $\mathrm{ND}$ & $22 \pm 1.2$ \\
& 5000 & $\mathrm{ND}$ & $20 \pm 0.27$ \\
& 50000 & $24 \pm 0.22$ & $19 \pm 0.61$ \\
$59 \pm 2.5$ & 17.3 & $\mathrm{ND}$ & $53 \pm 1.7$ \\
& 173 & $\mathrm{ND}$ & $60 \pm 0.54$ \\
& 1725 & $70 \pm 0.29$ & $62 \pm 0.26$ \\
$97 \pm 3$ & 4.88 & $\mathrm{ND}$ & $64 \pm 3.7$ \\
& 48.8 & $\mathrm{ND}$ & $90 \pm 2.3$ \\
& 488 & $108 \pm 0.53$ & $94 \pm 0.19$
\end{tabular}

${ }^{a}$ Geometric diameters for 59 and $97 \mathrm{~nm} \mathrm{NPs}$ and hydrodynamic diameter for the $21 \mathrm{~nm}$ NPs as given by manufacturers. ${ }^{b}$ Mean values \pm one standard deviation $(N=3) .{ }^{c} \mathrm{ND}$ denotes not determined.

Table 4. Au Concentration and Au NP Recoveries from Selected Rat Liver Samples

$\begin{array}{ccc}\text { dosage group } & \begin{array}{c}\text { Au concentration }(\mathrm{ng} \mathrm{Au} / \mathrm{g} \\ \text { fresh liver })^{a, b}\end{array} & \begin{array}{c}\text { recovery } \\ (\%)^{a, c}\end{array} \\ \text { control } & <340 & \\ 42.4 \mu \mathrm{g} \text { as } 10 \mathrm{~nm} \text { Au NPs } & 1565 \pm 601 & 123 \% \pm 46 \% \\ 41.3 \mu \text { g as } 60 \mathrm{~nm} \text { Au NPs } & 3106 \pm 1188 & 88 \% \pm 30 \% \\ 41.7 \mu \mathrm{g} \text { as a mixture of } 10 \text { and } & 3097 \pm 230 & 86 \% \pm 1.2 \% \\ 60 \mathrm{~nm} \mathrm{Au} \mathrm{NPs} & & \end{array}$

${ }^{a}$ Mean values \pm one standard deviation of repeated analysis of the same liver homogeneate $(N=3) .{ }^{b}$ Aqua regia digested livers. ${ }^{c}$ Tetramethylammonium hydroxide extracted livers.

TMAH, as previously used for determination of molecular mercury species in fish. ${ }^{28,29}$ Liberation of nanoparticles from biological tissue into suspension, however, has not been carried out previously by this technique. The stability of Au NPs in suspension may, however, be compromised when dispersed in solutions with high ionic strength such as the TMAH solution. To prevent agglomeration, serum albumin has proven effective for steric stabilization of Au NPs ${ }^{30-32}$ by way of establishing a protein corona on their surface. Therefore, BSA was added to all sample homogenates and to aqueous suspensions of Au NPs prior to the alkaline sample pretreatment. In contrast, if BSA was not first added to the Au NPs suspensions, precipitation of $\mathrm{Au}$ NPs was visible by color change from red to blue and later by observation of a dark precipitate. Furthermore, a color change from red to colorless and precipitation of Au NPs was observed when the more energetic microwave-assisted extraction was used at $90{ }^{\circ} \mathrm{C}$ for $20 \mathrm{~min}$ even if BSA had been added prior to addition of the alkaline reactant. The TMAH extraction method, therefore, had to be conducted using the milder conditions at room temperature.

The two separated peaks in the $\mathrm{AF}^{4}$-ICPMS fractogram (Figure 5), which corresponded to $\mathrm{Au}$ NPs suspended in aqueous TMAH solution illustrated that the 10 and $60 \mathrm{~nm} \mathrm{Au}$ NPs were successfully separated by $\mathrm{AF}^{4}$ using the BSA stabilization procedure (Figure 5). Furthermore, the retention times obtained for the 10 and $60 \mathrm{~nm}$ Au NPs in TMAH solution were

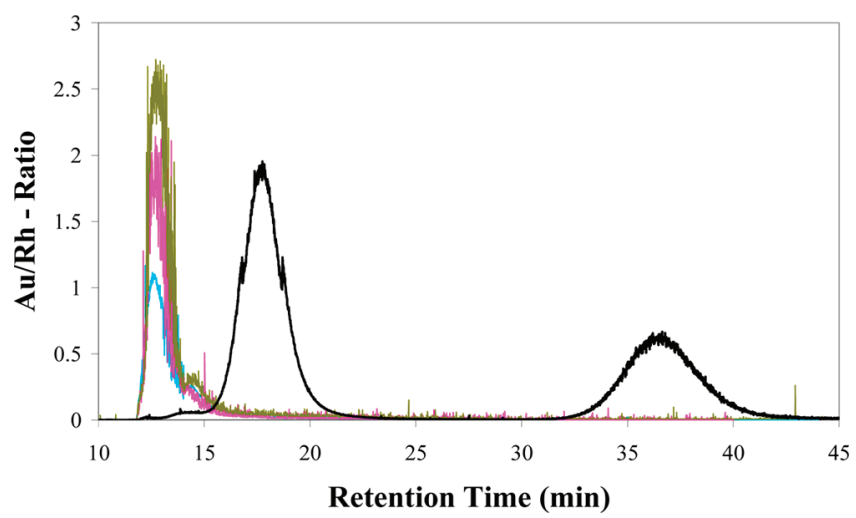

Figure 5. Overlaid $\mathrm{AF}^{4}$-ICPMS fractograms corresponding to three rat liver samples and a suspension of BSA-stabilized 10 and $60 \mathrm{~nm} \mathrm{Au} \mathrm{NPs}$ in aqueous TMAH solution (black line). The fractograms corresponds to liver samples from the three dosage groups (see Table 4). The blue line indicates the $10 \mathrm{~nm}$ Au NP dosage group; the pink line indicates the $60 \mathrm{~nm} \mathrm{Au} \mathrm{NP} \mathrm{dosage} \mathrm{group,} \mathrm{and} \mathrm{the} \mathrm{green} \mathrm{line} \mathrm{indicates} \mathrm{the} \mathrm{dosage}$ group with a mixture of 10 and $60 \mathrm{~nm}$ Au NPs.

identical to those obtained for an aqueous Au NP suspension (Figure 2) and demonstrated that the virgin particles indeed were stable. In contrast, the fractograms corresponding to the liver extracts showed that the 10 and $60 \mathrm{~nm}$ Au NPs eluted unresolved at a $T_{\mathrm{r}}$ of $13 \mathrm{~min}$, which was close to the void volume (Figure 5). In order to understand this nonideal elution, TEM images indicated that $\mathrm{Au}$ NPs were associated with amourphous dark residues of the tissue (Figure $4 \mathrm{C}$ ), which may have caused the observed non-Brownian (steric) elution in $\mathrm{AF}^{4}$. The TEM image also revealed that the Au NPs in the alkaline liver extract did not agglomerate and occurred individually with the same size as observed for the mixture of stock suspensions of Au NPs (Figure 4B). In order to achieve size separation of the $\mathrm{Au}$ NPs by $\mathrm{AF}^{4}$, however, further development of sample preparation methods for more complete liberation of Au NPs from biological tissue was warranted.

\section{CONCLUSIONS}

A hyphenated instrumental platform consisting of $\mathrm{AF}^{4}$ with MALS and DLS detection coupled to ICPMS was established and successfully used for separation and quantitative characterization of PS and Au NPs. The determined size of the separated NPs, which was based on online DLS and MALS measurements, gave values in accordance with stated or certified values. Quantification of the separated Au NPs by the ICPMS corresponded to mean recoveries of $50 \%, 95 \%$, and $67 \%$ for the 10,20 , and $60 \mathrm{~nm}$ $\mathrm{Au}$ NPs, respectively. The incomplete recoveries were partially caused by adhesion to instrument surfaces but not caused by agglomeration of Au NPs. Detection limits for Au NPs analyzed by the hyphenated platform were at the subnanogram level.

For the first time, intact $\mathrm{Au}$ NPs were detected in rat livers after alkaline (TMAH) extraction. Using the platform, Au NPs were recovered from rat livers ranging from $86 \%$ to $123 \%$ of their total Au content. Separation of 10 and $60 \mathrm{~nm}$ Au NPs contained in the alkaline liver extracts was, however, not possible due to association of $\mathrm{Au}$ NPs with remains of liver tissue. Electron microscopy used for imaging of Au NPs was a useful tool for revealing sources of error and supplying additional information regarding the findings by the hyphenated platform. 


\section{ASSOCIATED CONTENT}

S Supporting Information. Additional information as noted in text. This material is available free of charge via the Internet at http://pubs.acs.org.

\section{AUTHOR INFORMATION}

\section{Corresponding Author}

*Fax: +45 35887448. E-mail: ehlar@food.dtu.dk.

\section{ACKNOWLEDGMENT}

We thank The Danish Strategic Research Council through the NanoPack project and University of Copenhagen for supporting this work. Furthermore, Lizzie Eriksen, Birgitte Koch Herbst, Liljana Petrevska, and the staff from the animal care unit are thanked for technical assistance. Daniel Some from Wyatt Technology Corporation, Santa Barbara, CA, USA, is acknowledged for valuable discussions of light scattering data.

\section{REFERENCES}

(1) Daniel, M. C.; Astruc, D. Chem. Rev. 2004, 104, 293-346.

(2) Frens, G. Nature: Phys. Sci. 1973, 241, 20-22.

(3) Enustun, B. V.; Turkevich, J. J. Am. Chem. Soc. 1963, $85,3317-3328$.

(4) Giljohann, D. A.; Seferos, D. S.; Daniel, W. L.; Massich, M. D.; Patel, P. C.; Mirkin, C. A. Angew. Chem., Int. Ed. Engl. 2010, 49, 3280-3294.

(5) Oberdörster, G. J. Intern. Med. 2010, 267, 89-105.

(6) Oberdörster, G.; Stone, V.; Donaldson, K. Nanotoxicology. 2007, $1,2-25$.

(7) Scheffer, A.; Engelhard, C.; Sperling, M.; Buscher, W. Anal. Bioanal. Chem. 2008, 390, 249-252.

(8) Tiede, K.; Boxall, A. B. A.; Tiede, D.; Tear, S. P.; David, H.; Lewis, J. J. Anal. At. Spectrom. 2009, 24, 964-972.

(9) Degueldre, C.; Favarger, P. Y.; Wold, S. Anal. Chim. Acta 2006, 555, 263-268.

(10) Chen, Y. S.; Hung, Y. C.; Lin, W. H.; Huang, G. S. Nanotechnology 2010, 21, 195101.

(11) Patra, C. R.; Bhattacharya, R.; Mukherjee, P. J. Mater. Chem. 2010, 20, 547-554.

(12) Giddings, J. C. Sep. Sci. 1966, 1, 123-125.

(13) Hassellöv, M.; Lyvén, B.; Haraldsson, C.; Sirinawin, W. Anal. Chem. 1999, 71, 3497-3502.

(14) Ranville, J. F.; Hendry, M. J.; Reszat, T. N.; Xie, Q.; Honeyman, B. D. J. Contam. Hydrol. 2007, 91, 233-246.

(15) Bolea, E.; Gorriz, M. P.; Bouby, M.; Laborda, F.; Castillo, J. R.; Geckeis, H. J. Chromatogr., A 2006, 1129, 236-246.

(16) Stolpe, B.; Hassellöv, M.; Andersson, K.; Turner, D. R. Anal. Chim. Acta 2005, 535, 109-121.

(17) Worms, I. A. M.; Szigeti, Z. A. G.; Dubascoux, S.; Lespes, G.; Traber, J.; Sigg, L.; Slaveykova, V. I. Water Res. 2010, 44, 340-350.

(18) Celine, C. L.; Lespes, G.; Dubascoux, S.; Aupiais, J.; Pointurier, F.; Potin-Gautier, M. J. Chromatogr., A 2009, 1216, 9113-9119.

(19) Lesher, E. K.; Ranville, J. F.; Honeyman, B. D. Environ. Sci. Technol. 2009, 43, 5403-5409.

(20) Bouby, M.; Geckeis, H.; Geyer, F. W. Anal. Bioanal. Chem. 2008, 392, 1447-1457.

(21) Montavon, G.; Bouby, M.; Huclier-Markai, S.; Grambow, B.; Geckeis, H.; Rabung, T.; Pashalidis, I.; Amekraz, B.; Moulin, C. J. Colloid Interface Sci. 2008, 327, 324-332.

(22) Lyvén, B.; Hassellöv, M.; Haraldsson, C.; Turner, D. R. Anal. Chim. Acta 1997, 357, 187-196.

(23) Von der Kammer, F.; Baborowski, M.; Tadjiki, S.; Von Tumpling, W. Acta Hydrochim. Hydrobiol. 2004, 31, 400-410.
(24) Dubascoux, S.; Le Hecho, I.; Hassellöv, M.; Von der Kammer, F.; Gautier, M. P.; Lespes, G. J. Anal. At. Spectrom. 2010, 25, 613-623.

(25) Sharp, B. L. J. Anal. At. Spectrom. 1988, 3, 613-652.

(26) Allain, P.; Jaunault, L.; Mauras, Y.; Mermet, J. M.; Delaporte, T. Anal. Chem. 1991, 63, 1497-1498.

(27) Schure, M. R.; Schimpf, M. E.; Schettler, P. D. In Field-Flow Fractionation Handbook; Schimpf, M., Caldwell, K., Giddings, J. C., Eds.; Wiley-Interscience: New York, 2000; pp 32-48.

(28) Nevado, J.J. B.; Martin-Doimeadios, R. C. R.; Bernardo, F. J. G.; Moreno, M. J. J. Chromatogr., A 2005, 1093, 21-28.

(29) Reyes, L. H.; Rahman, G. M. M.; Fahrenholz, T.; Kingston, H. M. S. Anal. Bioanal. Chem. 2008, 390, 2123-2132.

(30) Bihari, P.; Vippola, M.; Schultes, S.; Praetner, M.; Khandoga, A. G.; Reichel, C. A.; Coester, C.; Tuomi, T.; Rehberg, M.; Krombach, F. Part. Fibre Toxicol. 2008, 5, 14.

(31) Buford, M. C.; Hamilton, R. F., Jr.; Holian, A. Part. Fibre Toxicol. 2007, 4, 6.

(32) Sager, T. M.; Porter, D. W.; Robinson, V. A.; Lindsley, W. G.; Schwegler-Berry, D. E.; Castranova, V. Nanotoxicology 2007, 1, 118-129. 